Revista Destaques Acadêmicos, Lajeado, v. 12, n. 3, 2020. ISSN 2176-3070

DOI: http://dx.doi.org/10.22410/issn.2176-3070.v12i3a2020.2639

http://www.univates.br/revistas

\title{
FATORES QUE GERAM ESTRESSE AOS PROFISSIONAIS DA ENFERMAGEM NO SETOR DE URGÊNCIA E EMERGÊNCIA: UMA REVISÃO INTEGRATIVA
}

\author{
Paula Fernanda Jantsch ${ }^{1}$, Cássia Regina Gotler Medeiros², \\ Paula Michele Lohmann ${ }^{3}$
}

Resumo: O presente estudo objetivou identificar, na produção científica existente, fatores relacionados ao estresse da equipe de enfermagem em unidade de urgência e emergência. Trata-se de uma revisão integrativa da literatura, realizada na BVS-Bireme (Biblioteca Virtual em Saúde), pelas bases de dados MEDLINE (Medical Literature Analysis and Retrieval System Online), LILACS (Literatura Latino-Americana e do Caribe em Ciências da Saúde) e portal da SciELO (Scientific Eletronic Library Online), em maio de 2020, considerando artigos em português, publicados no período de 2014 a 2019, a partir da leitura dos artigos norteada pela seguinte questão: fatores relacionados ao estresse da equipe de enfermagem na unidade de urgência e emergência. A busca pelos artigos resultou, inicialmente, em 19 produções, e, a partir do estabelecimento dos critérios de inclusão e exclusão, o corpus desta revisão constituiu-se em seis artigos. Os principais resultados evidenciaram que existem vários fatores que geram estresse nos profissionais da enfermagem no setor de urgência e emergência, entre eles se destacam a carga horária, o atendimento a crianças, o acúmulo de atividades, a falta de profissionais e a organização do setor. Conclui-se que o serviço de urgência e emergência é considerado um ambiente de trabalho iminentemente estressante por causa da sobrecarga física e/ou mental aos trabalhadores, com efeitos na vida profissional e particular do trabalhador.

Palavras-chave: Enfermagem em emergência. Estresse ocupacional. Enfermagem.

1 Enfermeira, pós-graduanda em Enfermagem em Urgência e Emergência, Universidade do Vale do Taquari - Univates, Lajeado/RS. paulinha_jantsch@hotmail.com

2 Doutora em Enfermagem, docente titular da Univates, Lajeado/RS. cgotlermedeiros@gmail.com

3 Enfermeira, doutoranda em Ambiente e Desenvolvimento e docente do Curso de Enfermagem da Univates, Lajeado/RS. paulalohmann@univates.br 


\section{INTRODUÇÃO}

O serviço de urgência e emergência, eixo deste estudo, é considerado um ambiente de trabalho iminentemente estressante por causa da sobrecarga física e/ou mental aos trabalhadores, com efeitos patogênicos na saúde (GOMES; SANTOS; CAROLINO, 2013). O estresse é popularmente chamado de mal do século, e pela sua amplitude ocupa um lugar de destaque nos meios de comunicação, encaixando-se como um problema de saúde pública, com impacto negativo na vida dos trabalhadores (OLIVEIRA et al., 2013).

Em 2012, a Organização Mundial de Saúde (OMS) relatou que 90\% da população sofre de estresse, pois se vive em um tempo de constante atualização e informações. O estresse é identificado como um estado de tensão que causa ruptura no equilíbrio interno do organismo, sendo identificado, em sua fase inicial, mediante uma série de sinais e sintomas psicossomáticos, tais como taquicardia, gastrite, alterações cardiovasculares e insônia. Sendo assim, o organismo procura o auto equilíbrio, necessitando realizar um esforço especial para estabelecer a homeostase, exigindo, assim, considerável desgaste e utilização de reservas de energia física e mental (OLIVEIRA et al., 2013).

$\mathrm{O}$ enfermeiro exerce uma atividade durante sua jornada de trabalho que lhe exige responsabilidade, concentração, organização do setor e equipe, e assistência/cuidado ao paciente/cliente. Com tantas funções para desempenhar, mais a especificidades próprias do trabalho, pode se desenvolver um estado de estresse e, decorrente disso, afetar no trabalho, na saúde e na qualidade de vida do enfermeiro. Dentro deste contexto, a literatura presume que o trabalho do enfermeiro pode ser um gerador de estresse ocupacional (ROCHA; MARTINO, 2010).

A palavra "estresse" é usada para explicar inúmeros acontecimentos que assolam a humanidade nos dias atuais. O estresse ocorre quando há uma modificação ameaçadora, lesiva ou tensa no ambiente, desencadeando um desequilíbrio no indivíduo. $\mathrm{O}$ indivíduo sente ou se torna incapaz de realizar tarefas sob essa situação; esse estímulo causador de tal situação é o fator estressor, sendo variável: o fator estressor que gera estresse em um indivíduo pode não gerar em outro (STACCIARINI, TRÓCCOLI; 2001).

A resposta fisiológica a um estressor é um processo de proteção e adaptação ao organismo, para manter a homeostasia. $\mathrm{O}$ estressor altera a homeostasia, resultando em doença, dada uma falha na adaptação ao estresse, a resposta psicológica consiste na reação do individuo para controlar a situação de estresse, denominado de processo de mediação. Quando o estresse resulta em consequências ao aparelho psíquico dos trabalhadores, denomina-se Síndrome de Burnout (SELEGHIM et al., 2012).

Burnout é um termo usado para caracterizar o estresse ocupacional, causado por falta de energia. Ocorre um sentimento de fracasso e exaustão, dado 
o desgaste excessivo de energia, acometendo, principalmente, profissionais que trabalham em contato direto com pessoas (JODAS; HADDAD, 2009).

A síndrome de Burnout é um dos maiores problemas psicossociais nos dias atuais, o alto estresse gera sofrimento, o que traz consequências à saúde $\mathrm{e}$ ao desempenho profissional da pessoa acometida (JODAS; HADDAD, 2009).

Neste sentido, o presente estudo objetivou identificar, na produção científica existente, fatores relacionados ao estresse da equipe de enfermagem em unidade de urgência e emergência.

\section{METODOLOGIA}

Trata-se de uma revisão integrativa da literatura. A busca pelos artigos foi realizada utilizando os termos "Enfermagem em emergência", "Estresse ocupacional" e "Enfermagem", com o emprego do operador booleano "and", na BVS-Bireme (Biblioteca Virtual em Saúde), pelas bases de dados MEDLINE (Medical Literature Analysis and Retrieval System Online), LILACS (Literatura Latino-Americana e do Caribe em Ciências da Saúde) e portal da SciELO (Scientific Eletronic Library Online). A busca ocorreu em maio de 2020, a partir da leitura dos artigos norteada pela seguinte questão: fatores relacionados ao estresse da equipe de enfermagem na unidade de urgência e emergência. $O$ período de publicação dos artigos foi de 2014 a 2019.

Os critérios de inclusão foram artigos que abordam a temática pesquisada, com disponibilidade online e gratuitamente do texto na íntegra e no idioma português. Foram excluídos os estudos que não contemplavam a pergunta norteadora da pesquisa. Para o acesso ao texto completo, foram usados os seguintes recursos: link disponível diretamente na própria base de dados selecionada, busca no portal do periódico em que o artigo foi publicado.

A pesquisa resultou, inicialmente, nos seguintes números nas referidas bases de dados: um artigo na MEDLINE, doze na LILACS e seis na SciELO, totalizando 19 produções. Por fim, a partir do estabelecimento dos critérios de inclusão e exclusão, o corpus desta revisão constituiu-se em quatro artigos na LILACS e dois na SciELO, totalizando seis artigos. A primeira etapa de análise do material foi realizada por meio de leitura e construção do quadro sinóptico. Para construção do quadro, foram extraídas as seguintes variáveis: número, base de dados ou portal, autor(s)/ano, título, periódico, procedência dos estudos e delineamento da pesquisa.

Os dados foram analisados por categorias temáticas conforme proposto por Bardin (2011), sendo que na fase de interpretação dos resultados avaliaramse as convergências e divergências existentes à luz de diferentes autores. Quanto aos aspectos éticos, ressalta-se que os preceitos de autoria e as citações dos autores das publicações que constituíram a amostra foram respeitados. 


\section{RESULTADOS E DISCUSSÃO}

$\mathrm{Na}$ presente revisão integrativa, analisaram-se seis artigos que contemplaram a questão norteadora e os critérios de inclusão, sendo que estes foram analisados na íntegra, a fim de caracterizá-los, interpretá-los e discutilos. Inicialmente, serão apresentados e caracterizados os artigos selecionados por meio do Quadro 1 (Dados sobre os artigos). Após, serão apresentados os principais resultados encontrados nos artigos selecionados por meio de categorias temáticas que nortearam a produção de conhecimento sobre fatores relacionados ao estresse da equipe de enfermagem na unidade de urgência e emergência.

As informações dos artigos encontrados seguem no quadro a seguir.

\section{Quadro 1 - Dados sobre os artigos}

\begin{tabular}{|c|c|c|c|c|c|c|}
\hline N. & $\begin{array}{c}\text { Base de } \\
\text { dados ou } \\
\text { portal }\end{array}$ & $\begin{array}{c}\text { Autor(s) / } \\
\text { ano }\end{array}$ & Título de trabalho & Periódico & $\begin{array}{l}\text { Procedência } \\
\text { do estudo }\end{array}$ & $\begin{array}{l}\text { Delineamento } \\
\text { da pesquisa }\end{array}$ \\
\hline $\mathrm{A} 1$ & BVS & $\begin{array}{l}\text { Santos et } \\
\text { al. (2019) }\end{array}$ & $\begin{array}{l}\text { Estresse ocupacional: } \\
\text { exposição da equipe } \\
\text { de enfermagem de } \\
\text { uma unidade de } \\
\text { emergência }\end{array}$ & $\begin{array}{l}\text { Revista Online } \\
\text { de Pesquisa: } \\
\text { Cuidado é } \\
\text { Fundamental }\end{array}$ & Bahia & $\begin{array}{l}\text { Qualitativo } \\
\text { exploratório } \\
\text { descritivo }\end{array}$ \\
\hline A2 & BVS & $\begin{array}{l}\text { Kolhs et al. } \\
\text { (2017) }\end{array}$ & $\begin{array}{l}\text { A enfermagem na } \\
\text { urgência e emergência: } \\
\text { entre o prazer e o } \\
\text { sofrimento }\end{array}$ & $\begin{array}{l}\text { Revista Online } \\
\text { de Pesquisa: } \\
\text { Cuidado é } \\
\text { Fundamental }\end{array}$ & $\begin{array}{c}\text { Santa } \\
\text { Catarina }\end{array}$ & $\begin{array}{c}\text { Estudo } \\
\text { qualitativo, } \\
\text { descritivo, } \\
\text { estudo de caso }\end{array}$ \\
\hline A3 & BVS & $\begin{array}{l}\text { Angelim } \\
\text { e Rocha } \\
(2016)\end{array}$ & $\begin{array}{l}\text { Produção científica } \\
\text { acerca das condições } \\
\text { de trabalho da } \\
\text { enfermagem em } \\
\text { serviços de urgência e } \\
\text { emergência }\end{array}$ & $\begin{array}{l}\text { Revista Online } \\
\text { de Pesquisa: } \\
\text { Cuidado é } \\
\text { Fundamental }\end{array}$ & & $\begin{array}{c}\text { Revisão } \\
\text { integrativa }\end{array}$ \\
\hline A4 & Portal & $\begin{array}{l}\text { Fonseca } \\
\text { e Neto } \\
(2014)\end{array}$ & $\begin{array}{l}\text { Níveis de estresse } \\
\text { ocupacional e } \\
\text { atividades estressoras } \\
\text { em enfermeiros } \\
\text { de unidades de } \\
\text { emergência }\end{array}$ & $\begin{array}{l}\text { Revista Rene } \\
\text { (Revista } \\
\text { da Rede de } \\
\text { Enfermagem } \\
\text { do Nordeste) }\end{array}$ & Manaus & $\begin{array}{l}\text { Desenho } \\
\text { epidemiológico, } \\
\text { transversal }\end{array}$ \\
\hline A5 & SciELO & $\begin{array}{l}\text { Loro et al. } \\
\text { (2016) }\end{array}$ & $\begin{array}{l}\text { Desvelando situações } \\
\text { de risco no contexto } \\
\text { de trabalho da } \\
\text { Enfermagem em } \\
\text { serviços de urgência e } \\
\text { emergência }\end{array}$ & $\begin{array}{l}\text { Escola Anna } \\
\text { Nery }\end{array}$ & $\begin{array}{l}\text { Rio Grande } \\
\text { do Sul }\end{array}$ & $\begin{array}{c}\text { Estudo } \\
\text { descritivo } \\
\text { exploratório }\end{array}$ \\
\hline A6 & BVS & $\begin{array}{l}\text { Oliveira et } \\
\text { al. (2017) }\end{array}$ & $\begin{array}{l}\text { Estresse ocupacional } \\
\text { e burnout em } \\
\text { enfermeiros de um } \\
\text { serviço de emergência: } \\
\text { a organização do } \\
\text { trabalho }\end{array}$ & $\begin{array}{l}\text { Revista } \\
\text { enfermagem } \\
\text { Uerj }\end{array}$ & $\begin{array}{l}\text { Rio de } \\
\text { janeiro }\end{array}$ & $\begin{array}{c}\text { Estudo } \\
\text { quantitativo } \\
\text { descritivo do } \\
\text { tipo transversal }\end{array}$ \\
\hline
\end{tabular}

Fonte: Da pesquisa, 2020. 
Analisando os artigos desta revisão, foram constatadas diversas situações que podem gerar estresse nos profissionais da enfermagem no serviço de urgência e emergência. Conforme artigo A6 (OLIVEIRA et al., 2017), que traz o contexto da Síndrome de Burnout, este é um dos maiores problemas psicossociais nos dias atuais. $\mathrm{O}$ alto estresse gera sofrimento, que traz consequências na saúde e no desempenho profissional da pessoa acometida. Seus sinais e sintomas são exaustão física, psíquica e emocional, diminuição da realização pessoal no trabalho e despersonalização. Ocorre quando há exigência de alta qualificação intelectual, envolvendo tomadas de decisões importantes, com alto peso emocional, ocorrendo principalmente em pessoas que exercem profissões desgastantes durante muitos anos, com carga horária excessiva e em ambiente altamente estressante.

Conforme os artigos A1 (SANTOS et al., 2019) e A2 (KOLHS et al., 2017), a quantidade de funcionários para prestar os cuidados aos pacientes de forma humanizada é insuficiente, o que gera ansiedade e sentimento de impotência nos profissionais. Essa sobrecarga é resultante da elevada demanda de pacientes, do insuficiente número de profissionais no setor, da quantidade de serviço por pessoa, da elevada carga horária destes profissionais e da correria.

Seguindo esse contexto, esses dois artigos ressaltam a falta de reconhecimento pelos pacientes e acompanhantes pelo trabalho realizado pela enfermagem e somando a pressão e sobrecarga de trabalho que a equipe de enfermagem sofre pelos acompanhantes dos pacientes é mais um fator que gera estresse e cansaço.

O artigo A2 (KOLHS et al., 2017) também ressalta que o atendimento infantil é identificado como estressante pelos profissionais, pois às vezes não apresentam treinamento específico para prestar um atendimento adequado, causando, dessa forma, um sentimento de sofrimento e angústia na hora do atendimento; traz ainda a morte de pacientes como uma questão de sofrimento e estresse para equipe, pois coloca a luta pela vida como uma grande responsabilidade.

O artigo A5 (LORO et al., 2016) enfatiza alguns relatos encontrados no artigo A1 (SANTOS et al., 2019), e refere que no setor de urgência e emergência o tempo é restrito para o atendimento, as atividades são inúmeras e, na maioria das vezes, a situação clínica dos usuários exige que o profissional faça tudo para afastá-lo do risco iminente de morte. Desse modo, a enfermagem vivencia a sobrecarga relacionada ao contato direto com o sofrimento de pacientes, dor, morte, ritmo de trabalho intenso, múltiplas tarefas, fatores que podem ter influência no desgaste mental desse profissional.

Ainda o artigo A5 (LORO et al., 2016) destaca outro fator considerável para o estresse, que são as recorrentes mudanças de setor e a alteração da rotina como o trabalho noturno, que também é um agravante para o estresse. O sono perdido, muitas vezes, não consegue ser compensado e, quando persistente e 
com efeito cumulativo, pode desencadear a diminuição da capacidade mental e o cansaço físico é inevitável.

O artigo A3 (ANGELIM; ROCHA, 2016) relata um estudo realizado com enfermeiros que trabalhavam em uma emergência hospitalar, ressaltando que profissionais mais antigos estão menos predispostos a apresentar estresse no trabalho que os novos.

Já o artigo A4 (FONSECA; NETO, 2014) segue a linha do artigo A1 (SANTOS et al., 2019), e refere que o estresse que ocorre no ambiente de trabalho nos setores de emergência pode ser prejudicial para a saúde e qualidade de vida do enfermeiro, e não somente para o contexto de trabalho. Assim, o estresse sofrido no trabalho exige que o enfermeiro encontre mecanismos de confrontamento que favoreçam o controle do estresse, de modo que contribuam para redução dos sintomas físicos e psicológicos.

Ainda no artigo A4 (FONSECA; NETO, 2014), entre as atividades relacionadas como as mais estressoras estão o funcionamento adequado da unidade, administração do pessoal, e os fatores ambientais dos setores de urgência e emergência, que podem contribuir para a evolução dos sintomas de estresse e influenciar o trabalho dos profissionais de forma negativa.

\section{CONSIDERAÇÕES FINAIS}

Este estudo permitiu revelar os fatores relacionados ao estresse da equipe de enfermagem em unidades de urgência e emergência, identificando as atividades que os mesmos desenvolvem e que geram estresse na unidade. Por ser um estudo de revisão integrativa, suas limitações estão associadas à busca em descritores definidos pelos autores.

Os resultados demonstraram que os fatores que mais geram estresse na unidade são a sobrecarga de trabalho, a falta de profissionais e atendimentos pediátricos. O enfermeiro exerce uma atividade durante sua jornada de trabalho que lhe exige responsabilidade, concentração, organização do setor e equipe, além da assistência.

Conclui-se que o serviço de urgência e emergência é considerado um ambiente de trabalho iminentemente estressante por causa da sobrecarga física e/ou mental aos trabalhadores, com efeitos na vida profissional e particular do trabalhador, uma vez que, no seu cotidiano, o profissional de enfermagem se depara com diversos fatores que ocasionam estresse no ambiente de trabalho.

\section{REFERÊNCIAS}

ANGELIM, R. C. M.; ROCHA, G. S. A. Produção científica acerca das condições de trabalho da enfermagem em serviços de urgência e emergência. Cuidado é Fundamental, v. 8, n. 1, p. 3845-3859, jan./mar. 2016. Disponível em: <>. Acesso em: 10 maio 2020. 
BARDIN, L. Análise de conteúdo. São Paulo: Edições 70, 2011. 229 p.

FONSECA, J. R. F.; NETO, D. L. Níveis de estresse ocupacional e atividades estressoras em enfermeiros de unidades de emergência. Revista Rene, v. 15, n. 5, p. 732-742, set./out. 2014. Disponível em: <http:/ / periodicos.ufc.br/rene/article/ view/3230>. Acesso em: 10 maio 2020.

GOMES, S. F.; SANTOS, M. M.; CAROLINO, E. T. Riscos psicossociais no trabalho: estresse e estratégias de coping em enfermeiros em oncologia. Revista LatinoAmericana de Enfermagem [online], v. 21, n. 6, p. 1282-1289, 2013. Disponível em: <https: / / www.scielo.br/scielo.php?pid=S0104-11692013005000006\&script=sci_ abstract\&tlng=pt>. Acesso em: 15 abr. 2020.

JODAS, D. A.; HADDAD, M. C L. Síndrome de Burnout em trabalhadores de enfermagem de um pronto socorro de hospital universitário. Acta Paulista de Enfermagem, São Paulo, v. 22, n. 2, p. 192-197, 2009.

KOLHS, M. et al. A enfermagem na urgência e emergência: entre o prazer e o sofrimento. Cuidado é Fundamental, v. 9, n. 2, p. 422-431, abr./jun. 2017. Disponível em: <http:/ / seer.unirio.br/index.php/cuidadofundamental/article/view/5427>. Acesso em: 10 maio 2020.

LORO, M. M. et al. Desvelando situações de risco no contexto de trabalho da Enfermagem em serviços de urgência e emergência. Escola Anna Nery, Rio de Janeiro, v. 20, n. 4, jan. 2016. Disponível em: <http://www.scielo.br/scielo.php?script=sci arttext\&pid=S1414-81452016000400204\&lng=en\&nrm=iso $>$. Acesso em: 10 maio 2020.

OLIVEIRA, J. D. et al. Representações sociais de enfermeiros acerca do estresse laboral em um serviço de urgência. Revista da Escola de Enfermagem da USP, v. 47, n. 4, p. 984-989, ago. 2013.

OLIVEIRA, E. B. et al. Estresse ocupacional e burnout em enfermeiros de um serviço de emergência: a organização do trabalho. Revista Enfermagem Uerj, Rio de Janeiro, v. 25, 2017. Disponível em: <https:/ / www.e-publicacoes.uerj.br/index.php/ enfermagemuerj/article/view/28842/22382>. Acesso em: 10 maio 2020.

ROCHA, M. C. P.; MARTINO, M. M. F. O estresse e qualidade de sono do enfermeiro nos diferentes turnos hospitalares. Revista da Escola de Enfermagem da USP [online], v. 44, n.2, p. 280-286, 2010. Disponível em: <https:/ / www.scielo.br/scielo. php?pid=S0080-62342010000200006\&script=sci_abstract\&tlng=pt $>$. Acesso em: 13 abr. 2020.

SANTOS, J. N. M. O. et al. Estresse ocupacional: exposição da equipe de enfermagem de uma unidade de emergência. Cuidado é Fundamental, v. 11, n. esp., p. 455-463, 2019. Disponível em: <http://www.seer.unirio.br/index.php/cuidadofundamental/ article/view/6386/pdf_1>. Acesso em: 10 maio 2020. 
SELEGHIM, M. R. et al. Sintomas de estresse em trabalhadoras de enfermagem de uma unidade de pronto socorro. Revista Gaúcha de Enfermagem, Porto Alegre, v. 33. n. 3, p. 165-173, set. 2012.

STACCIARINI, J. M. R.; TRÓCCOLI, B.T. O estresse na atividade ocupacional do enfermeiro. Revista Latino-Americana de Enfermagem [online], v. 9, n. 2, mar. 2001. Disponível em: <https:/ / www.scielo.br/scielo.php?pid=S0104$11692001000200003 \&$ script=sci_abstract\&tlng=pt>. Acesso em: 4 jun. 2020. 